\title{
Clinical potential of SLAMF7 antibodies - focus on elotuzumab in multiple myeloma
}

This article was published in the following Dove Press journal:

Drug Design, Development and Therapy

20 March 2017

Number of times this article has been viewed

\author{
Reed Friend \\ Manisha Bhutani \\ Peter M Voorhees \\ Saad Z Usmani \\ Department of Hematologic \\ Oncology \& Blood Disorders, Levine \\ Cancer Institute, Carolinas Healthcare \\ System, UNC School of Medicine, \\ Charlotte, NC, USA
}

\begin{abstract}
Elotuzumab is one of the first monoclonal antibodies to be approved for the treatment of multiple myeloma. It is a humanized immunoglobulin G kappa (IgGK) antibody that targets signaling lymphocytic activation molecule family member 7 (SLAMF7), a surface marker that is highly expressed on normal and malignant plasma cells. This review summarizes the preclinical and clinical data that led to the approval of elotuzumab, along with a discussion on the ongoing and future clinical investigations.
\end{abstract}

Keywords: multiple myeloma, relapsed, refractory, treatment, elotuzumab, SLAMF7, CS1

\section{Introduction}

Multiple myeloma (MM) is a clonal plasma cell malignancy that usually presents with a monoclonal protein in serum or urine, anemia, renal insufficiency and bone disease. Although MM represents $\sim 10 \%$ of hematologic malignancies in the US with a median age of 69 years at diagnosis, the annual incidence of MM has been rising steadily over the past decade in the US, with a projected 30,000 new cases in $2016 .{ }^{1}$ This may be primarily driven by the increment in the proportion of the aging population coupled with an increased awareness about the disease due to the development of novel agents for treatment of MM. In comparison with the 1990s, the survival of MM patients has increased 4-fold, but many patients experience disease relapse and may eventually develop disease that is refractory to all approved agents. ${ }^{1}$ Therefore, there remains an impetus to understand drug resistance mechanisms and develop novel drug classes and treatment strategies based on disease biology. During relapse, patients may present with different burdens of disease and clinical symptoms that may also be complicated by other co-morbidities (diabetes, heart disease, chronic obstructive pulmonary disease, etc.) - this adds another dimension to the intricacy of their care.

Immunotherapy is a broad terminology applied to several strategies being employed in cancer medicine. These strategies include monoclonal antibodies (mAbs), antibody-drug conjugates and various adoptive cellular therapies (vaccines, natural killer [NK] cells, T cells, dendritic cells, etc.), with the last deemed as the most bona fide "immunotherapy" approach. The mAbs may target the cancer cell, its micro-environment or the immune system (eg, checkpoint inhibition). With the success of mAb therapy in the treatment of solid and hematologic malignancies, several targets are now being explored in MM. In this review, we focus on signaling lymphocytic activation molecule family member 7 (SLAMF7) as a therapeutic target in $\mathrm{MM}$ and the relevant preclinical and clinical data of the approved anti-SLAMF7 $\mathrm{mAb}$ elotuzumab (Elo).
Correspondence: Saad Z Usmani Levine Cancer Institute, Carolinas Healthcare System, UNC School of Medicine, Charlotte, NC, USA Email saad.usmani@carolinashealthcare. org 


\section{SLAMF7 - expression on human cells and function}

SLAMF7 is a signaling lymphocytic activation molecule F7, previously known as cell surface 1, CS1 (CCND3 subset 1 , CD2-like receptor-activating cytotoxic cells [CRACC]). It is a cell surface protein and a member of the signaling lymphocytic activation molecule family, which has been identified on NK cells and is critical for NK cell functions such as adhesion. ${ }^{2}$ By examining the expressed sequence tag database for CD2-like molecules, ${ }^{3}$ a novel leukocyte cell surface receptor of the CD2 family called CRACC was identified. CRACC appears to trigger the NK cell-mediated cytotoxicity through a unique SLAM-associated proteinindependent extracellular signal-regulated kinase (ERK)dependent pathway. ${ }^{3}$ Hsi et al ${ }^{4}$ confirmed that other normal lymphocyte subsets, such as NK cells, NK-like T cells, CD $8^{+}$ $T$ cells, activated monocytes and dendritic cells, also express SLAMF7, although at lower levels than normal plasma cells. In 2008, they showed that normal plasma cells and MM cells express high levels of SLAMF7 messenger RNA (mRNA) and protein. This observation eventually led to the development of a panel of murine and humanized mAbs to human SLAMF7 to validate this protein as a potential target for the treatment of MM. ${ }^{4}$

\section{SLAMF7 - expression on malignant PCs}

Both plasma cells and MM cells appear to express high levels of SLAMF7 mRNA and protein, an observation confirmed in animal models, human cell lines and primary patient samples. ${ }^{4,5}$ This high expression of SLAMF7 on human MM cells appears to be independent of the presence of metaphase cytogenetic abnormalities or molecular subgroup by gene expression profiling. ${ }^{4}$ It was with this in mind Hsi et al developed a panel of murine and humanized mAbs to human SLAMF7 to validate this protein as a potential target for the treatment of MM. SLAMF7 was analyzed by gene expression profiling and immunohistochemistry of both normal and MM patient samples. Interestingly, it has been observed that the SLAMF7 gene is located on chromosome 1q, amplifications of which are frequent in aggressive myeloma and linked to early myeloma-related death in part due to overexpression of the cell cycle regulator $C K S 1 B .^{6}$

\section{Elo - preclinical data}

Elo is a humanized IgGK mAb that targets SLMAF7. It mediates MM cell killing via NK cell activation first demonstrated by Tai et $\mathrm{al}^{5}$ who showed that the novel humanized anti-SLAMF7 mAb HuLuc63 induced antibody-dependent cellular cytotoxicity (ADCC) against human MM cells (Figure 1). ${ }^{5}$ The same group also found that gene expression of SLAMF7 appears most highly in primary myeloma cells and cell lines and is not detected at significant levels in normal tissues and nonmalignant cells. Elo showed in vivo efficacy in mouse xenograft models of MM by inhibition of MM cell adhesion to bone marrow stromal cells. ${ }^{4,5}$ Although this activity was limited as a single agent in preclinical studies, immunomodulatory agents such as lenalidomide appeared to enhance the preclinical efficacy of Elo through their potentiation of NK-cell-mediated ADCC and immune function. Furthermore, the combination of Elo with different classes of agents, such as the proteasome inhibitor bortezomib, has been shown to enhance immune lysis of myeloma by enhancing Elo-mediated antibody-dependent

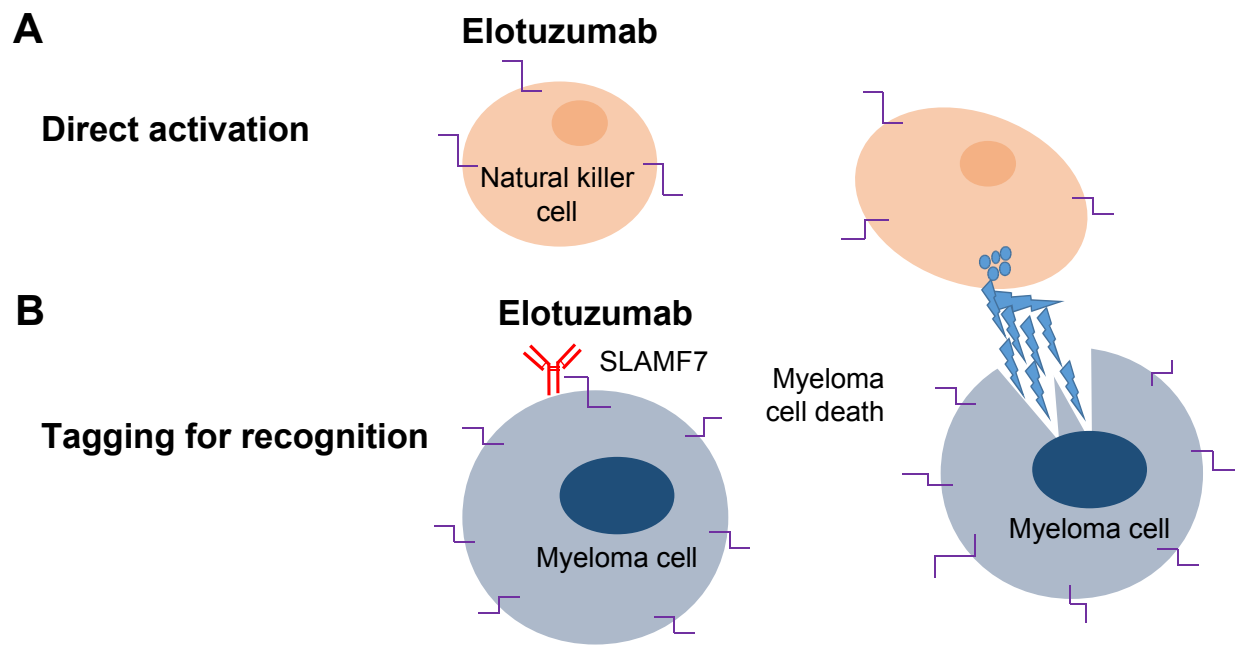

Figure I Elotuzumab: proposed mechanism of action in myeloma.

Notes: (A) Direct natural killer (NK) cell activation by elotuzumab. (B) Antibody-dependent NK cell-mediated cytotoxicity.

Abbreviation: SLAMF7, signaling lymphocytic activation molecule family member 7. 
cell-mediated cytotoxicity. ${ }^{6}$ Based on the preclinical rationale mentioned earlier, Elo moved into early phase clinical development.

\section{Elo - clinical data and Phases I, II and III}

In the first human Phase I, multicenter, open-label, dose escalation study by Zonder et $\mathrm{al}^{7}{ }^{7}$ the safety of single-agent Elo was studied in relapsed and refractory MM patients. Thirty-five patients with relapsed/refractory MM were enrolled into 6 escalating dose cohorts, with intravenous Elo doses ranging from 0.5 to $20 \mathrm{mg} / \mathrm{kg}$ once every 14 days. Trial eligibility included adults aged $\geq 18$ years with a diagnosis of relapsed/refractory MM who had received at least 2 prior MM therapies. No maximum tolerated dose (MTD) was identified up to the maximum planned dose (MPD) of $20 \mathrm{mg} / \mathrm{kg}$. The most common adverse events were primarily infusion related and mild to moderate in severity. To reduce the risk of an infusion-related reaction, the study was amended to include a premedication regimen of methylprednisolone, diphenhydramine and acetaminophen before the first dose of Elo in the $20 \mathrm{mg} / \mathrm{kg}$ dosing group. Additional dosing of diphenhydramine and acetaminophen was given on as-needed basis to subsequent cycles. Of the 34 patients treated, 25 completed the initial 8-week treatment. Eight went on to receive another 8 weeks of therapy. Findings revealed that SLAMF7 on bone marrow-derived plasma cells was reliably saturated ( $\geq 95 \%$ ) at the 10 and $20 \mathrm{mg} / \mathrm{kg}$ dose levels. Nine patients $(26.5 \%)$ had stable disease. Results from this study formed the framework for further investigation of Elo in combination with other MM therapies (Table 1). ${ }^{7}$

In parallel, another Phase I, multicenter, open-label, dose escalation trial was initiated to evaluate the MTD, safety and efficacy of Elo in combination with bortezomib. Patients were required to have received 1-3 prior lines of MM therapy. Bortezomib was given at $1.3 \mathrm{mg} / \mathrm{m}^{2}$ intravenously (IV) on days 1, 4, 8 and 11 of a 21-day cycle along with Elo in 4 dose-escalating doses ranging from 2.5 to $20 \mathrm{mg} / \mathrm{kg}$ IV within 30 minutes of bortezomib infusion on days 1 and 11 of each cycle. This study was also amended to include premedication regimens to minimize infusion reactions following a grade 3 infusion reaction of hypersensitivity. Twenty-eight patients were enrolled with 27 evaluable for response based on the European Group for Blood and Marrow Transplantation (EBMT) criteria. Eleven patients had received prior bortezomib therapy and $13 \mathrm{had}$ received prior

Table I Published elotuzumab clinical trials

\begin{tabular}{|c|c|c|c|c|c|c|}
\hline Study & Regimen & $\begin{array}{l}\text { Study design } \\
\text { (no of participants) }\end{array}$ & $\begin{array}{l}\text { Median } \\
\text { prior lines of } \\
\text { treatment }\end{array}$ & Response & PFS & Significant AEs \\
\hline Lonial et al ${ }^{9}$ & EloRd & Phase I $(n=28)$ & 3 & 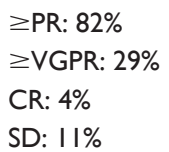 & NR & $\begin{array}{l}\text { Fatigue: } 61 \% \\
\text { Grade } 3 / 4 \text { : neutropenia }(36 \%) \text {, } \\
\text { thrombocytopenia }(21 \%)\end{array}$ \\
\hline Zonder et $\mathrm{al}^{7}$ & Elo & Phase I $(n=35)$ & 4.5 & $\begin{array}{l}\geq \text { PR: } 0 \% \\
\geq \text { VGPR: } 0 \% \\
\text { SD: } 28.5 \%\end{array}$ & $N R$ & $\begin{array}{l}\text { IRR before institution of infusion } \\
\text { prophylaxis: } 52 \%\end{array}$ \\
\hline Jakubowiak et al ${ }^{8}$ & V + Elo & Phase I $(n=28)$ & 2 & $\begin{array}{l}\geq \text { PR: } 48 \% \\
\geq \text { VGPR: } 7 \%\end{array}$ & 9.5 months & \\
\hline Richardson et al" & $\begin{array}{l}\text { EloRd } 10 \mathrm{mg} / \mathrm{kg} \\
\text { versus EloRd } \\
20 \mathrm{mg} / \mathrm{kg}\end{array}$ & $\begin{array}{l}\text { Phase lb/ll } \\
(n=36) \\
(n=37)\end{array}$ & $\begin{array}{l}\geq 2 \\
\geq 2\end{array}$ & $\begin{array}{l}\geq \text { PR: } 36 \% \\
\geq \text { VGPR: } 43 \% \\
\text { CR: } 4 \%\end{array}$ & 32.9 months & $\begin{array}{l}78 \% \text { had grade } 3-4 \text { AEs: lymphopenia } \\
(21 \%) \text {, neutropenia }(19 \%)\end{array}$ \\
\hline Jakubowiak et al ${ }^{10}$ & $E B d$ versus $B d$ & $\begin{array}{l}\text { Phase II } \\
(n=77) \\
(n=75)\end{array}$ & $\begin{array}{l}1 \\
1\end{array}$ & $\begin{array}{l}\geq \text { PR: } 65 \% \\
\text { VGPR: } 30 \% \\
\text { CR: } 4 \% \\
\text { यPR: } 63 \% \\
\text { VGPR: } 23 \% \\
\text { CR: } 4 \%\end{array}$ & $\begin{array}{l}9.7 \text { months } \\
\text { I-year OS: } 85 \% \\
6.9 \text { months } \\
\text { I-year OS: } 74 \%\end{array}$ & $\begin{array}{l}\text { IRR in elotuzumab group: } 7 \% \text { (all grade } \\
\text { I/2); most common grade } 3-4 \text { AEs } \\
\text { were infections (EBd } 21 \%, \mathrm{Bd} 13 \% \text { ) and } \\
\text { thrombocytopenia (EBd } 9 \%, \mathrm{Bd} 17 \% \text { ) }\end{array}$ \\
\hline $\begin{array}{l}\text { Lonial et al }{ }^{12} \\
\text { (ELOQUENT-2) }\end{array}$ & $\begin{array}{l}\text { EloRd } 10 \mathrm{mg} / \mathrm{kg} \\
\text { versus Rd }\end{array}$ & $\begin{array}{l}\text { Phase III } \\
(n=32 I) \\
(n=325)\end{array}$ & $\begin{array}{l}2 \\
2\end{array}$ & 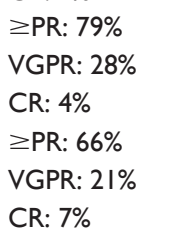 & $\begin{array}{l}19.4 \text { months } \\
\text { I } 4.9 \text { months }\end{array}$ & $\begin{array}{l}\text { Grade } 3 / 4 \text { lymphopenia: } 77 \% \\
\text { Herpes zoster: } 4.1 \text { per } 100 \text { patient-years } \\
\text { IRR: I0\% (mostly grade I/2) } \\
\text { Grade } 3 / 4 \text { lymphopenia: } 49 \% \\
\text { Herpes zoster: } 2.2 \text { per } 100 \text { patient-years }\end{array}$ \\
\hline
\end{tabular}

Abbreviations: PFS, progression-free survival; AE, adverse event; EloRd, elotuzumab, lenalidomide and dexamethasone; Rd, lenalidomide and dexamethasone; PR, partial response; VGPR, very good partial response; CR, complete response; SD, stable disease; EBd, Elo, bortezomib and dexamethasone; Bd, bortezomib and dexamethasone; OS, overall survival; NR, not reported; IRR, infusion related reaction. 
lenalidomide. Patients were treated with a median of 6 cycles, ranging from 1 to 32 . The most frequent grade 3-4 adverse events included lymphopenia (25\%), fatigue (14\%), thrombocytopenia, neutropenia, hyperglycemia, pneumonia and peripheral neuropathy $(11 \%$ each $) .{ }^{8}$ The objective response rate (ORR) was $48 \%$ and median time-to-progression (TTP) was 9.46 months (Table 1).

Jakubowiak et al pursued a randomized, Phase II study evaluating the efficacy of Elo combined with bortezomib and dexamethasone. Progression-free survival (PFS) was the primary end point. A total of 150 patients were treated with either EBd (Elo, bortezomib, dexamethasone) or Bd (bortezomib, dexamethasone) in a 1:1 ratio, stratified according to prior proteasome inhibitor therapy, presence of at least 2 Fc $\gamma$ RIIIa $\mathrm{V}$ alleles and number of prior lines of MM therapy (1-3). ${ }^{10}$ Treatment schema included bortezomib $1.3 \mathrm{mg} / \mathrm{m}^{2}$ IV or subcutaneously administered on days 1, 4, 8 and 11 for cycles $1-8$ and then on days 1,8 and 15 thereafter along with Elo $10 \mathrm{mg} / \mathrm{kg}$ IV weekly with the first 2 cycles followed by days 1 and 11 for cycles 3-8 and then on days 1 and 15 thereafter. Treatment was continued until disease progression or intolerable toxicity. Premedication of dexamethasone $20 \mathrm{mg}$ was administered orally on non-Elo-dosing days and as $8 \mathrm{mg}$ orally plus $8 \mathrm{mg}$ IV on Elo-dosing days. Approximately half of the patients included in this study had received prior bortezomib therapy. With the use of premedication, there were no grade 3-4 infusion-related reactions in this study. The most common grade 3-4 adverse events were infections (EBd 21\%, Bd 13\%) and thrombocytopenia (EBd 9\%, Bd 17\%). Two on-study deaths occurred in the EBd group versus 6 patients in the Bd group, the primary cause of death being disease in the EBd group. Although the ORR was comparable in both cohorts (EBd 66\%, Bd 63\%), updated analysis revealed that the response rate of very good partial response (VGPR) or better occurred in $36 \%$ of patients with EBd versus $27 \%$ of patients with $\mathrm{Bd}$. The study met its primary end point with a $28 \%$ reduction in the risk of progression or death with $\mathrm{EBd}$ compared to Bd and a median PFS of 9.7 months in the EBd cohort versus 6.9 months in the Bd cohort. In an updated analysis, the 2-year PFS rate was 18\% with EBd and 11\% with Bd (Table 1). Interestingly, those EBd-treated patients who were homozygous for the high-affinity Fc $\gamma$ RIIIa V allele were shown to have a significantly prolonged median PFS of 22.3 months compared with 9.8 months for those homozygous for the low-affinity Fc $\gamma R I I I a$ V allele. In contrast, the PFS was 8.2 and 6.9 months for Bd-treated patients homozygous for the high-affinity and low-affinity Fc $\gamma$ RIIIa V allele, respectively. ${ }^{10}$ This interesting observation will warrant further validation in ongoing and future prospective studies.
Following the above-mentioned Phase I study, an openlabel, multicenter, dose escalation Phase I study by Lonial et $\mathrm{al}^{9}$ evaluated escalating doses of Elo at 5,10 and $20 \mathrm{mg} / \mathrm{kg}$, administered intravenously in combination with lenalidomide and dexamethasone for relapsed and refractory MM patients. The primary objective of the study was to identify the MTD of Elo when combined with lenalidomide and dexamethasone. The MTD was defined as the highest dose of Elo at which 1 of 6 patients or fewer experienced a dose-limiting toxicity (DLT) during cycle 1. Elo was administered intravenously on days 1, 8, 15 and 22 for the first 2 treatment cycles and on days 1 and 15 for the remaining treatment cycles. Three patients were enrolled in 5, 10 and $20 \mathrm{mg} / \mathrm{kg}$ dose cohorts, beginning at the lowest dose level. If there were no DLTs during cycle 1, the next higher dose cohort could be enrolled. Additional patients who were enrolled were treated with either the MTD or the MPD of $20 \mathrm{mg} / \mathrm{kg}$ of Elo. The initial protocol included a treatment plan of 6 months, but with observed durable responses, treatment time was extended to disease progression. The median number of prior therapies was 3. Patients received a median of 10.5 treatment cycles. No DLTs were observed at the maximum proposed dose of $20 \mathrm{mg} / \mathrm{kg}$. It is notable that $89 \%$ of patients experienced at least one infusion reaction although most resolved on their own or following treatment with intravenous corticosteroids and premedications (diphenhydramine and ranitidine or equivalent). These reactions were mostly mild to moderate in severity and resolved the same day either with treatment or spontaneously. There were 2 patients who experienced a grade 3 or higher serious infusion reaction leading to treatment discontinuation. It is not clear whether all the patients were given premedication prior to infusion, although the authors make a point in their conclusion that the ongoing Phase II study would better define an improved premedication strategy. The ORR was $82 \%$ with $29 \%$ achieving at least a VGPR. A total of $11 \%$ of patients had stable disease with $7 \%$ having progressive disease. The response rate was similar regardless of the number of previous therapies received. However, the activity was most notable in the lenalidomidenaïve patients with a 95\% ORR. No first cycle DLT was observed in the dose-escalation phase to the maximum proposed dose of $20 \mathrm{mg} / \mathrm{kg}$. At a median of 16.4 months follow-up, the median TTP was not reached for those patients in the $20 \mathrm{mg} / \mathrm{kg}$ cohort (Table 1). ${ }^{9}$

Based on the encouraging safety and efficacy signal seen with Elo in combination with lenalidomide and dexamethasone in the above-noted Phase I study, ${ }^{9}$ a follow-up Phase II extension was implemented to further assess the efficacy of the combination and better characterize the optimal dose. ${ }^{11}$ 
Inclusion criteria included adults aged $>18$ years with relapsed/refractory $\mathrm{MM}$ who were treated with 1-3 prior lines of therapy. Seventy-three patients were assessed for eligibility into the Phase II portion, and all were enrolled to either Elo $10 \mathrm{mg} / \mathrm{kg}$ or Elo $20 \mathrm{mg} / \mathrm{kg}$ with Len/Dex. Treatment was administered in 28-day cycles given until disease progression or unacceptable toxicity. To minimize infusion reactions seen in the earlier studies, a premedication regimen was utilized that included dexamethasone given as a split dose (28 mg given orally 3-24 hours before Elo infusion and $8 \mathrm{mg}$ given IV 45 minutes before infusion), as well as an $\mathrm{H} 1$ blocker, an $\mathrm{H} 2$ blocker and acetaminophen all given 30-90 minutes prior to infusion. A total of 44 patients (split evenly between the 2 cohorts) had previous bortezomib exposure and 45 patients had previously been treated with thalidomide. Patients received a median of 17 cycles with a range of 1-51 cycles. Grade 3-4 treatment-emergent adverse events were noted in $73 \%$ of patients, with lymphopenia (21\%) and neutropenia (19\%) being the most common. Eighty-four percent achieved an objective response (92\% with the $10 \mathrm{mg} / \mathrm{kg}$ dosing and $72 \%$ with the $20 \mathrm{mg} / \mathrm{kg}$ dosing). Forty-two percent of patients enrolled achieved at least a VGPR by International Uniform Response criteria. The median PFS was an impressive 32.9 months. Most pertinent in this Phase Ib/II study was that the lower $10 \mathrm{mg} / \mathrm{kg}$ dosing had a higher ORR over the $20 \mathrm{mg} / \mathrm{kg}$ dosing validating later Phase III study dosing (Table 1).

Most recently, ELOQUENT-2, an open-label, multicenter Phase III study of lenalidomide and dexamethasone (Rd) versus Elo, lenalidomide and dexamethasone (EloRd) was conducted by Lonial et al. ${ }^{12}$ This study included adults $>18$ years old who were diagnosed with relapsed and/or refractory MM and had received 1-3 prior lines of therapy. A total of 646 patients were randomly assigned to either EloRd (321 patients) or Rd (325 patients). The median number of previous lines of therapy was 2 in both groups. Exposure to prior bortezomib and thalidomide therapy was similar between the 2 arms; 5 patients in the EloRd group and 6 patients in the Rd group received prior lenalidomide therapy. The median duration of treatment in the EloRd group was 17 and 12 months in the Rd group. The most common reason for therapy discontinuation was disease progression, $65 \%$ in the EloRd group and $79 \%$ in the Rd group. The most common grade 3-4 adverse events in the EloRd group were lymphopenia (77\%) and neutropenia (34\%) compared to $49 \%$ and $44 \%$, respectively, for those in the Rd group. The ORR in the EloRd group was $79 \%$ versus $66 \%$ in the $\mathrm{Rd}$ group. Twenty-eight percent in the EloRd group versus $21 \%$ in the $\mathrm{RD}$ group achieved a VGPR. Interestingly, the complete response (CR) in the EloRd group was $4 \%$ versus $7 \%$ in the $\mathrm{Rd}$ group, which could have been due to the fact that the therapeutic $\mathrm{mAb}$, detectable on serum protein electrophoresis and immunofixation assays, may have led to underestimation of the CR rate in the EloRd group. This phenomenon has also been observed in patients receiving another IgGK $\mathrm{mAb}$ such as daratumumab.

There was an improvement in PFS favoring the patients who received EloRd. Specifically, there was a relative reduction of $30 \%$ in the risk of disease progression or death compared to Rd alone. Median follow-up was 24.5 months with PFS at 1 year being $68 \%$ versus $57 \%$ favoring the EloRd group. ${ }^{12}$ Although not yet mature, preliminary overall survival data published thus far have recorded 210 deaths $(30 \%)$ in the EloRd group versus $116(37 \%)$ in the Rd group, representing $49 \%$ of the 427 deaths that are prespecified for final analysis. The fluorescence in situ hybridization (FISH) analyses were performed in a central laboratory upon study enrollment, which makes this trial unique compared to other Phase III trials in similar setting. It is notable that $32 \%$ of patients included in this study had the del $(17 p)$ variant $(17 p$ deletion), a poor prognostic biomarker in MM. The authors define del(17p) positivity without a cutoff noting that if any cell in the analyzed sample was positive for the mutation, the patient was considered del(17p) positive. The benefit of PFS in the Elo group was consistent across this key subgroup along with other typically poor outcome subgroups including patients aged $\geq 65$ years, patients with resistance to most recent therapy, with an international staging system (ISS) stage III disease at diagnosis, previous exposure to bortezomib or immunomodulatory drugs, and those patients with previous stem cell transplantation or with a creatinine clearance of $<60 \mathrm{~mL}$ per minute.

Based on these data reviewed, in November 2015, Elo in combination with lenalidomide and dexamethasone was approved by the FDA for use in MM patients who have received $1-3$ prior therapies.

\section{Future directions}

While the ELOQUENT-2 data are provocative, many patients are treated with lenalidomide-based therapy until disease progression as part of first-line therapy. Thus, many patients will be lenalidomide, immunomodulatory drug (IMiD) class refractory at the time of first relapse and may not be the ideal candidates for EloRd. Therefore, data perhaps need to be generated in the clinically relevant patient populations. There are several clinical trials examining the role of Elo combinations in the upfront treatment setting, maintenance setting and the relapsed/refractory setting (Table 2).${ }^{13}$ The most exciting of 


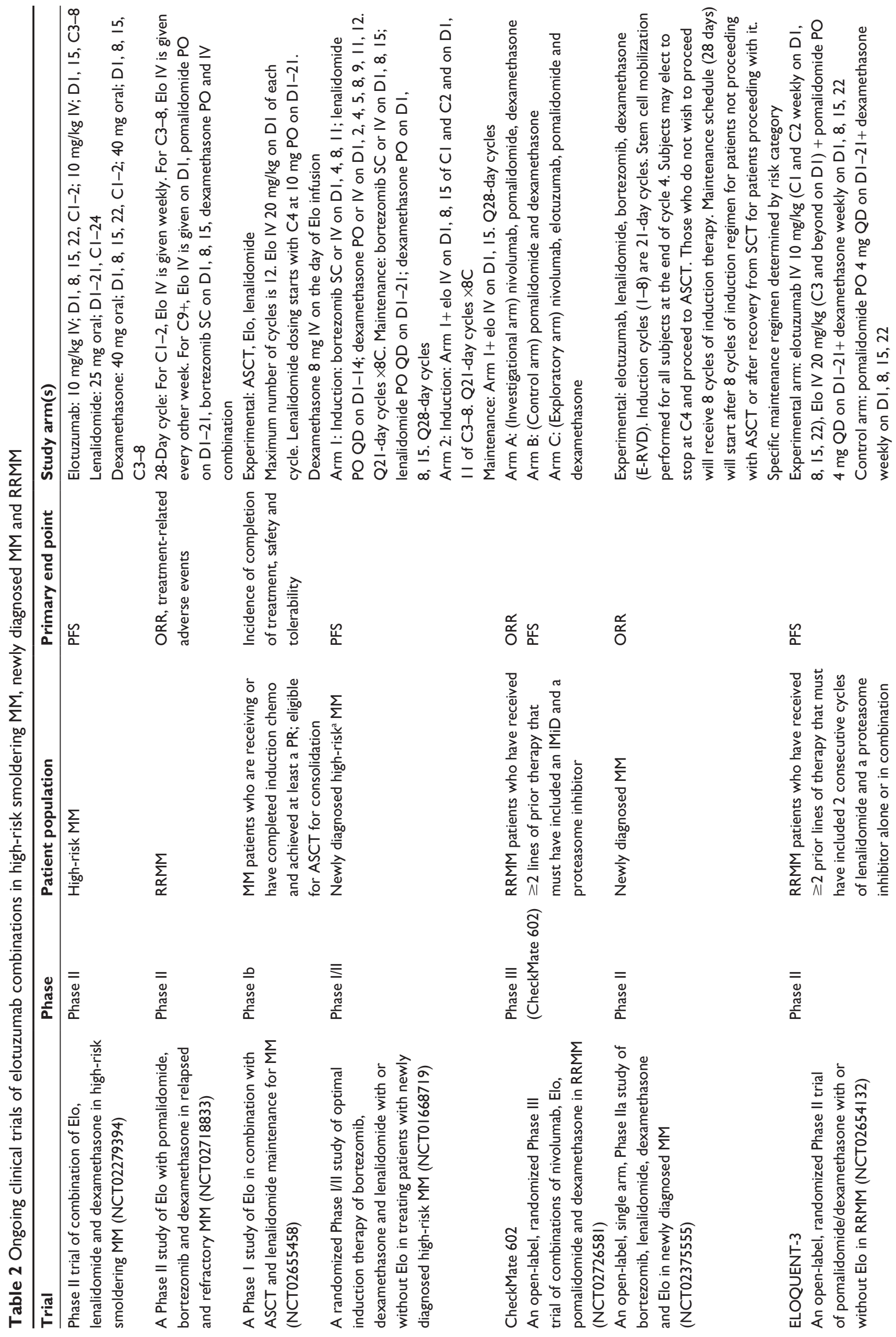



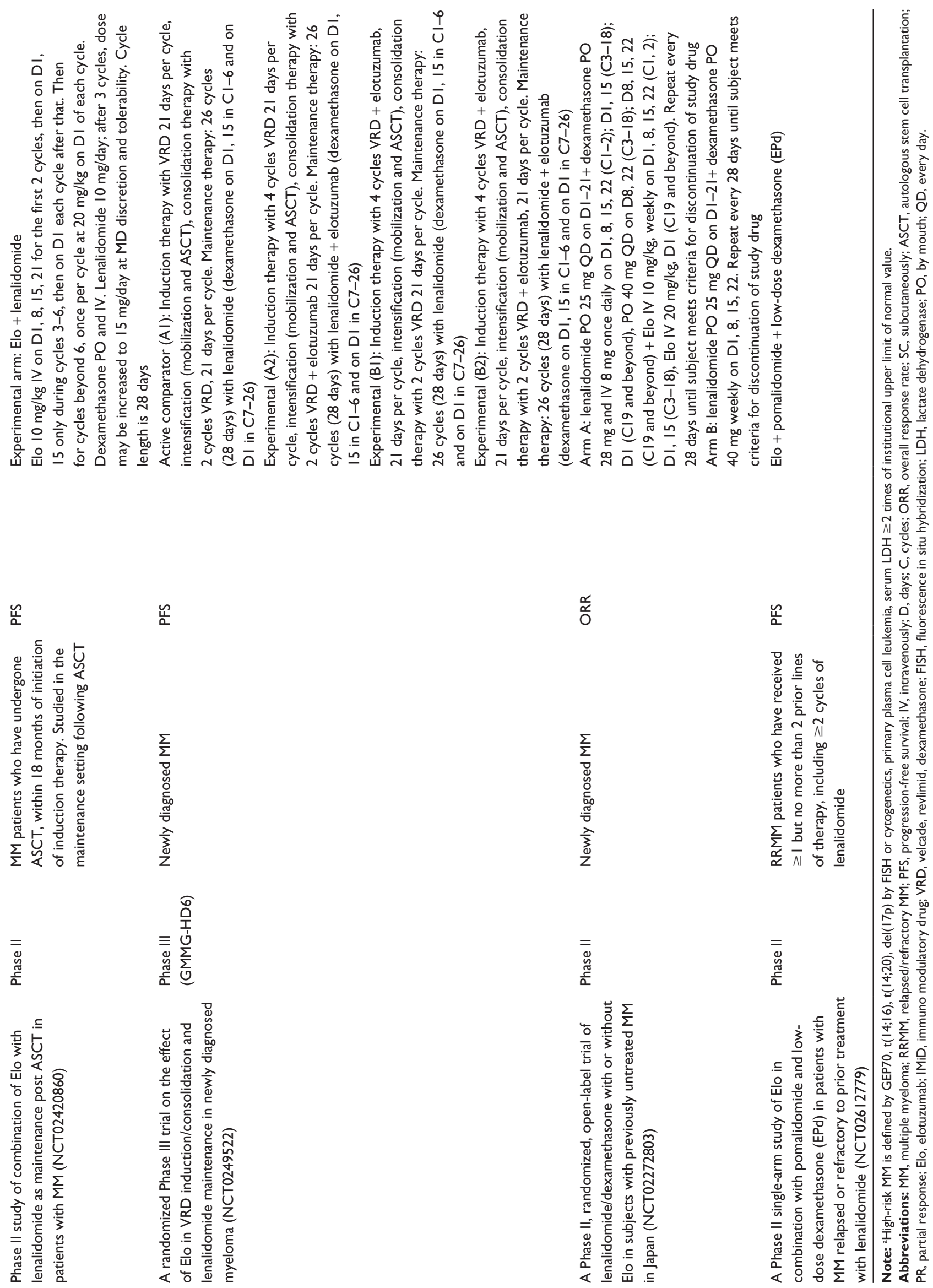
these combinations may be with other mAbs, especially the checkpoint inhibitor combination trials.

\section{Disclosure}

SZU has consulted for Amgen, Celgene, Takeda, Novartis, Janssen and Sanofi; received speaker fees for Celgene, Millennium Takeda and Onyx and received research funding from Amgen, Array Biopharma, Celgene, Janssen Oncology, Onyx, Pharmacyclics, Sanofi and Takeda. The other authors report no conflicts of interest in this work.

\section{References}

1. seer.cancer.gov [homepage on the Internet]. Available from: http://seer. cancer.gov/. Accessed November 4, 2016.

2. Lonial S. Monoclonal antibodies for the treatment of myeloma: targeting SLAMF7 and CD38. Cancer J. 2016;22(1):3-6.

3. Bouchon A, Cella M, Grierson HL, Cohen JI, Colonna M. Cutting edge: activation of NK cell-mediated cytotoxicity by a SAP-independent receptor of the CD2 family. J Immunol. 2001;167(10):5517-5521.

4. Hsi ED, Steinle R, Balasa B, et al. CS1, a potential new therapeutic antibody target for the treatment of multiple myeloma. Clin Cancer Res. 2008;14(9):2775-2784.

5. Tai Y-T, Dillon M, Song W, et al. Anti-CS1 humanized monoclonal antibody HuLuc63 inhibits myeloma cell adhesion and induces antibodydependent cellular cytotoxicity in the bone marrow milieu. Blood. 2008; 112(4):1329-1337.
6. van Rhee F, Szmania SM, Dillon M, et al. Combinatorial efficacy of anti-CS1 monoclonal antibody elotuzumab (HuLuc63) and bortezomib against multiple myeloma. Mol Cancer Ther. 2009;8(9):2616-2624.

7. Zonder JA, Mohrbacher AF, Singhal S, et al. A phase 1, multicenter, open-label, dose escalation study of elotuzumab in patients with advanced multiple myeloma. Blood. 2012;120(3):552-559.

8. Jakubowiak AJ, Benson DM, Bensinger W, et al. Phase I trial of antiCS1 monoclonal antibody elotuzumab in combination with bortezomib in the treatment of relapsed/refractory multiple myeloma. J Clin Oncol. 2012;30(16):1960-1965.

9. Lonial S, Vij R, Harousseau J-L, et al. Elotuzumab in combination with lenalidomide and low-dose dexamethasone in relapsed or refractory multiple myeloma. J Clin Oncol. 2012;30(16):1953-1959.

10. Jakubowiak A, Offidani M, Pégourie B, et al. Randomized phase 2 study: elotuzumab plus bortezomib/dexamethasone vs bortezomib/dexamethasone for relapsed/refractory MM. Blood. 2016;127(23):2833-2840.

11. Richardson PG, Jagannath S, Moreau P, et al; 1703 Study Investigators. Elotuzumab in combination with lenalidomide and dexamethasone in patients with relapsed multiple myeloma: final phase 2 results from the randomised, open-label, phase 1b-2 dose-escalation study. Lancet Haematol. 2015;2(12):e516-e527.

12. Lonial S, Dimopoulos M, Palumbo A, et al; ELOQUENT-2 Investigators. Elotuzumab therapy for relapsed or refractory multiple myeloma. N Engl J Med. 2015;373(7):621-631.

13. Weisel K. Spotlight on elotuzumab in the treatment of multiple myeloma: the evidence to date. Onco Targets Ther. 2016;9:6037-6048.
Drug Design, Development and Therapy

\section{Publish your work in this journal}

Drug Design, Development and Therapy is an international, peerreviewed open-access journal that spans the spectrum of drug design and development through to clinical applications. Clinical outcomes, patient safety, and programs for the development and effective, safe, and sustained use of medicines are the features of the journal, which

\section{Dovepress}

has also been accepted for indexing on PubMed Central. The manuscript management system is completely online and includes a very quick and fair peer-review system, which is all easy to use. Visit http://www.dovepress.com/testimonials.php to read real quotes from published authors. 